Chirurgia (2017) 112: 117-123

No. 2, March - April

Copyright@ Celsius

http://dx.doi.org/10.21614/chirurgia.112.2.117

\title{
Tendencies on Traditional Metrics
}

\author{
Daniel Ion ${ }^{1,2}$, Octavian Andronic', Alexandra Bolocan ${ }^{1,2}$, Rahim Al-Moushaly², Dan Nicolae Pădurarư ${ }^{1,2}$ \\ ${ }^{1}$ Carol Davila University of Medicine and Pharmacy, Bucharest, Romania \\ 23rd Department of General Surgery, Emergency University Hospital, Bucharest, Romania
}

Corresponding author:

Alexandra Bolocan, MD

3rd Department of General Surgery,

Emergency University Hospital

Bucharest, Romania

Email: bolocan.alexa@gmail.com
Abbreviations:

$\mathrm{IDB}=$ International Database

$|S|=$ Institute of Scientific Information

$J C R=$ Journal Citation Report

$\mathrm{JIF}=$ Journal Impact Factor

SCIE $=$ Science Citation Index Expanded

SJR $=$ SCImago Journal Rank

SNIP = Source Normalized Impact per

paper

$\mathrm{TR}=$ Thompson Reuters

WoS $=$ Web of Science

\section{Rezumat}

Tendințe privind parametrii scientometrici traditionali

Dinamica evoluției tehnologice a dus la creşterea exponențială a cantității de informații publicate în toate domeniile ştiințifice. În acest context a fost necesară dezoltarea unor metode obiective de a evalua revistele, articolele şi respectiv cercetătorii. Articolul de față reprezintă un review al evoluției parametrilor scientometrici tradiționali bazați pe citări.

Cuvinte cheie: metrici, factor de impact, $\mathrm{h}$ index, citare, evaluarea cercetării 


\section{Introduction}

Scientometrics is, very simplistically said, the science that analyses the impact of the science. A more rigorous definition is formulated by UNESCO, as being "the study of quantitative features and characteristics of science, scientific research and scholarly communications"(1).

Historically, scientometrics has its origins at the beginning of the 19th century (2), but, for the first time, it was defined as science by Nalimov in 1971 (3), therefore it represents a relatively new science in a very dynamic evolution process.

In order to understand the necessity of studying and knowing the scientometric notions, we must briefly remind the actual scientific context and its progress.

The first two science journals were founded in 1665 in Paris, respectively London (4). Since then, the number of science publications continuously and rapidly increased, until 1963, when there were more than 10000 science journals (5). Technological progress has led to the occurring of the concept of exclusively online journal, which has influenced the boom of the number of journals, boom that makes it impossible to exactly quantify their number. Therefore, in 2016, more than one million articles (6) were published in Pubmed, in more than 5500 journals (7). 8802 journals [9] were included in the Journal Citation Report 2015, Web of Science (WoS) platform indexed more than 1.6 million articles (8) and, in Scopus, more than 2.5 million documents (articles, books, etc.) were published in over 22000 journals (9).

Scientometrics allows us to analyse the impact of a paper, of a journal or of a research, which facilitates us to do anhierarchy, in an objective and statistically way, of various journals, research institutes, and universities and even of the researchers.

\section{Definitions}

It is necessary to define a series of terms in order to be able to present the scientometric parameters making the object of this paper.
Indexing represents listing a journal in a database, subsequent to a rigorous evaluation process.

An international database (IDB) is a portal containing abstracts, in extenso articles or only information on a certain journal. The database term is generic and very general because, depending on the facilities it puts at disposal, we may speak today of aggregators, research platforms, bibliometric databases etc.

The journal mark ISI (for scientific journals, medicine inclusively) refers at indexing a journal in the Science Citation Index Expanded (SCIE) database, held until 2016 by Thompson Reuters (TR) - in present it belongs to Clarivate Analytics. ISI acronym comes from the Institute of Scientific Information, founded in 1960 by Garfield and purchased in 1992 by Thompson Reuters (10). As regards the ISI journals, we must make a difference between an ISI-indexed journal and an ISI-rated journal. The second is a journal indexed in SCIE and which, additionally, it is included in the Journal Citation Reports (JCR).

Citation is defined as a reference to a text or part of a text identifying the document in which it may be found (11). The existence of numerous platforms indexing and publishing articles makes it difficult to quantify in only one place all the citations obtained by a certain article (12). Usually, a certain platform (for ex. WOS) takes into account only the citations from the articles it indexes to articles indexed as well.

Scientometric parameters may be defined depending on the subject that is exposed to analysis, in journal indexes, author indexes and respectively article indexes.

\section{Journal level metrics}

\section{Impact Factor}

The best known scientometric parameter by far is the impact factor. It was proposed by Garfield in 1955, in order to help the librarians evaluate the quality of journals $(10,13)$. Later on, it was adapted in order to be used as a facile method of selecting and indexing journals in the SCI database, founded by Garfield in 1960. 
The variant used by TR at present was created in 1995, under the acronym JIF (Journal Impact Factor) and defined as the ratio between the number of citations obtained in the year of calculation $(\mathrm{x})$ by the articles published in the previous 2 years $(x-1$ and $x-2)$ and the number of articles published in this period. JIF practically represents the average number of citations per article for all the articles published by a journal in the latest 2 years (for example, an impact factor 1 in 2016 means that each of the articles of 2014 and 2015 were cited once in 2016) $(14,15)$. There should be mentioned that the citations are taken into account if they come from journals indexed in SCIE (13) and the citations coming from the same journal (16) are also taken into account.

The impact factor varies a lot depending on the domain of the journal (17), for example, in JCR 2015, the higher impact factor of a medicine journal was 137.578 (CA-A Cancer Journal for Clinicians), being also the highest IF in 2015, at very large distance to the next one, with IF of 59.558 (New England Journal of Medicine). On the other side, the largest IF for a mathematical journal was 9 (ACTA NUMERICA) (8).

Another factor leading to IF variability is the predominant type of articles published (17). For example, the reviews accumulate a higher number of citations than the original articles that attract more citations than the casereports, which are rarely cited. At the same time, a series of document types - for example editorials, letters - cannot attract citations, but can generate citations (18).

The calculation window, of only 2 years, received a lot of critics claiming that this period is too short for a lot of domains. These critics are based on the fact that, in certain domains, such as mathematics, half-life citation has an average value of 10 years, and in others, such as medicine, it rarely exceeds the value of 5 years (19).

In time, JIF was used inappropriately and differently than the purpose it was proposed for. Individual evaluation of the researchers, universities or research institutes represents examples of incorrect use of JIF, as Garfield also mentioned (15).

There should be specified that JIF is calculated exclusively by WoS for the most important journals from SCIE and it is published in the Journal Citation Report (JCR) on a yearly basis. This mention should be made because a lot of platforms calculate indexes they abusively call impact factor which value is irrelevant.

\section{Eigenfactor}

Eigenfactor represents a new scientometric parameter, for the journals, proposed as an alternative at the impact factor. As principle of calculation, it is based on the number of citations and number of published articles (20), similar to IF.

The principle of calculating the Eigenfactor is based on an algorithm similar to pageranking of Google, considering citation instead of hyperlink. It practically starts from the premise that not all the citations are equal as influence. A citation is more important as it comes from a more influent journal. And a journal is more influent as it has citations coming from more influent journals (21).

Eigenfactor takes into account a period of 5 years before calculation and excludes selfcitations. It is also calculated starting from the data coming from the WoS database and it is published in JCR.

The method used to calculate Eighenfactor leads to the correction of discrepancies between various domains, and also the probability of attracting citations depending on the type of articles published (21).

\section{Article influence score}

The influence score was proposed by Carl Bergstrom and it is calculated as the ratio between the Eigenfactor and the number of articles published. The value of the ratio is later on normalized so that the influence score value of an article with an average influence should be 1 . In other words, an article with a value $\mathrm{x}$ of this parameter shall be $\mathrm{x}$ times more influent than the average (22). 


\section{SCImago Journal Rank (SJR)}

SCImago Journal Rank (SJR), developed by a group of researchers from the Grenada University, uses - as functioning principle -, similarly to Eigenfactor, an algorithm similar to page-ranking developed by Google and proposes to evaluate the visibility of a journal (23). Though, similarly to Eigenfactor, there are a few differences, among which calculation window, which is of only 3 years, comparatively to 5 years at Eigenfactor. Another difference is that it tends to be a qualitative index, not a quantitative one, being taken into account the value of citations, not their number (24).

From the point of view of self-citations, SJR admits self-citations in the limit of one third of total citations, thus admitting a process of self-citation considered within the normal limit (24).

It is calculated by Elsevier for the journals indexed in Scopus.

\section{Source Normalized Impact per paper (SNIP)}

It is a metric, normalized without defining limits for each individual science domain. The principle starts from the presumption that the domains where citations coming from journals with a large number of references have a high potential of citation, then the probability of being cited is higher (25).

As for the calculation method, it takes into account the citations in a certain year - $\mathrm{x}$ to articles published in the years $x^{-1}, x^{-} 2, x^{-} 3$ (26). It is calculated as the ratio of the number of citations and the potential number of citations.

It takes the domain, not the citation prestige, into consideration.

Similarly to SJR, it is published by Elsevier for the journals indexed in Scopus.

\section{Article level metrics}

The simplest way of evaluating the impact of an article is to quantify the total number of citations. Basically, the number of citations reveals the degree of interest of other researchers in the respective article, justified by the necessity to cite it. Though it is an article level metric, it has also been used as author or journal level parameter, by summing up. In practice, the number of citations is not used as parameter per se, but it is included in the calculation equations of other parameters (27).

Due to the large scale use of digital platforms, there are a series of metrics revealing the degree of utilisation of digital articles: number of downloading, number of viewing, utilisation of the document in the reference manager applications - Mendeley, and citation of articles in the social media Altmetrics.

\section{Author level metrics}

The traditional author level metrics have at their base the number of citations and the number of articles published by a certain author. The first parameter is deemed to be qualitative, because citations reveal the degree of interest of the scientific community in the published article, and the second one is deemed quantitative.

The relevance of the number of citations differs from several points of view: domain of the study, type of the article, visibility of the journal etc.

\section{h-index}

In 2005, Jorge Hirsch introduced a new index, intended to evaluate the scientific activity of a researcher. This index is defined as the number $\mathrm{h}$ - representing the minimum number of articles $-\mathrm{h}$, which have at least $\mathrm{h}$ citations.

The main advantage of the h-index is that it takes into account both the number of articles published and the number of citations, being considered both a quantitative and a qualitative index (28). Another advantage is that the $\mathrm{h}$ index is not exception-sensitive, such as articles with a very large number or very small number of citations, thus avoiding the results under- or over-rated (29).

In the article published by Hirsh in 2005 , he suggested that there might exist a causality 
relationship between the age of researchers and their $\mathrm{h}$ index (30). This link was studied in numerous later studies, which showed that, in practice, an average researcher would have an $\mathrm{h}$ index approximately equal to his age. The higher than the age the $\mathrm{h}$ index is, the more important his activity is.

The main disadvantages are: the presence of significant differences between researchers depending on the domain they activate and their age, the fact that does not take into account the difference between main author /co-authors and that it does not eliminate selfcitations (31).

The main difficulty in using author level metrics generally and $\mathrm{h}$ index particularly is the difficulty of making a difference between researchers with the same name and identical initial, thus, the verification becoming a time consuming process (32).

Subsequent to the analysis made and the study of the $\mathrm{h}$ index disadvantages, numerous variants of this index have been proposed, among which, the most known and used are: $\mathrm{g}$ index and $\mathrm{h}(2)$ index.

$\mathrm{G}$ index is defined as the largest number of articles $-\mathrm{g}-$ which, cumulatively, have more than g2 citations (33). This index has been proposed starting from the presumption that the differentiation between the authors with much cited articles is not a correct one, since the $\mathrm{h}$ index does not take into account the amplitude of the citations from the most cited articles. Thus, Egghe shows that the g index keeps all the advantages of the $\mathrm{h}$ index, and, besides, it solves a series of disadvantages (33).

$\mathrm{H}(2)$ index was proposed by Kosmulski in order to decrease the time necessary to check the author from the prism of name similarities. He defines $h(2)$ index as the largest number of articles $\mathrm{h}(2)$ which have at least $[\mathrm{h}(2)] 2$ cita- $^{-}$ tions each. More than that, he proposes generalisation towards a $\mathrm{h}(\mathrm{x})$ index, calculated with the same equation, with the intention of normalizing the indexes calculated in various domains, by using a $\mathrm{x}$ value specific to each domain (32).
Rousseau in 2006, shows that neither h-index, nor g-index offer a sufficiently wide image of the research activity, but, taken together, they present a concise and almost complete image of the publishing activity of an author (34). A study made in 2009 by Burrell concludes that all these three indexes seem to be proportional to the number of years of activity and it is difficult to specify which of those should be used in practice, because they may reveal different perspectives of the researchers' activities (35).

Two types of authors were proposed: mass producers with a lot of articles but few citations and influential/perfectionist with few articles, but many citations (36).

I10index is defined as the numbers of articles with at least 10 citations, considering all the citations and the citations newer than 2010 (37).

\section{Discussions}

In 2012, the Annual Meeting of the American Society for Cell Biology drafted and published a document called San Francisco Declaration on Research Assessment, which draws the attention on some errors of utilisation of scientometric parameters. The general recommendation is not to use the journal level metrics as a surrogate of the quality of articles in the individual evaluation of researchers in view to obtain promotions or financing (38).

In 2015, another document is published, The Leiden Manifesto for Research Metrics which lists ten principles having the role of guiding the use of scientometrics in the most correct and facile manner. Among these, we keep the main idea, that the quantitative evaluation, with indexes and metric parameters, should not replace and exclude qualitative evaluation, supplied by the experts of each domain (39).

Also in 2015, a report called The Metric Tide, draws attention, among others, on the risk of using exclusively quantitative elements in research evaluation (40). 


\section{Conclusions}

Considering the data presented above, which focuses on a lot of advantages, disadvantages and lacks we can draw a series of conclusions:

- Scientometric evaluation must be used together with qualitative evaluation of the experts, without excluding the latter.

- Comparison of researchers, journals or institutions should be made separately, depending on their domain and dimension, or by means of normalized indexes.

- Scientometric parameters have suffered a lot of changes in time, being it difficult to create an ideal evaluation method which would not have any disadvantages.

- There should be considered that the scientometric parameters take into account the data coming exclusively from certain platforms (Eigenfactor, JCR of SCIE, SNIP, IPP of Scopus etc,), which might lead to inaccurate or inexact data. Therefore, it is important to take into account several parameters coming from various platforms.

- Data interpretation should be made by persons with advanced knowledge in the domain of scientometrics, in order to avoid mistakes or interpretation errors.

\section{References}

1. UNESCO. Research evaluation metrics. 2015.

2. Godin B. On the origins of bibliometrics. Scientometrics [Internet]. 2006;68(1):109-33. Available from: http://dx.doi.org/10.1007/ s11192-006-0086-0

3. Mingers J, Leydesdorff L. A Review of Theory and Practice in Scientometrics. European Journal of Operational Research. 2015; 246(1):1-19. DOI: 10.1016/j.ejor.2015.04.002

4. Ash L. A History of Scientific and Technical Periodicals: The Origins and Development of the Scientific and Technological Press, 16651790. Bull Med Libr Assoc [Internet]. 1962 Jul;50(3):631-2. Available from: http://www.ncbi.nlm.nih.gov/pmc/articles /PMC197881/

5. Price DJ de S. Little science, big science...and beyond. New York: Columbia University Press; 1986.

6. No Title [Internet]. Available from: https://www.ncbi.nlm.nih.gov/ pubmed/?term $=2016 \% 3$ A2016

7. No Title [Internet]. Available from: https://www.nlm.nih.gov/bsd /num_titles.html

8. Web of Science Website [Internet]. [cited 2016 Jan 14]. Available from: http://apps.webofknowledge.com

9. Scopus Website [Internet]. [cited 2016 Jan 14]. Available from: www.scopus.com

10. Agarwal A, Durairajanayagam D, Tatagari S, Esteves SC, Harlev A, Henkel $R$, et al. Bibliometrics: tracking research impact by selecting the appropriate metrics. Asian J Androl. 2016;18(2):296309. doi: $10.4103 / 1008-682 X .171582$.

11. Prytherch R. Harrod's Librarians' Glossary and Reference Book. 10th ed. United Kingdom: Ashgate Publishing Group; 2009.

12. Seglen PO. Citations and journal impact factors: questionable indicators of research quality. Allergy. 1997;52(11):1050-6.

13. Garfield E. Journal impact factor: a brief review. CMAJ. 1999 161(8):979-980

14. Garfield E. The Thomson Reuters Impact Factor [Internet]. 1994. Available from: http://wokinfo.com/essays/impact-factor/

15. Garfield E. The Agony and the Ecstasy - The History and Meaning of the Journal Impact Factor. 2005 [cited 2016 Dec 17]; Available from: www.eugenegarfield.org

16. Kear R, Colbert-Lewis D. Citation searching and bibliometric measures. Coll Res Libr News [Internet]. 2011 [cited 2017 Jan 15]; 72(September):470-4. Available from: http://ezproxy.library.wisc.edu /login?url=http://search.ebscohost.com/login.aspx?direct=true\&db=IIf $\& A N=525475627 \&$ site $=$ ehost-live

17. van Leeuwen T. Discussing some basic critique on Journal Impact Factors: revision of earlier comments. Scientometrics. 2012;92(2): 443-455. Epub 2012 Feb 29

18. Azer S, Holen A, Wilson I, Skokauskas N. Impact factor of medical education journals and recently developed indices: Can any of them support academic promotion criteria? J Postgrad Med. 2016; 62(1):32-9. doi: 10.4103/0022-3859.173202.

19. Campanario JM, Miguel J. Empirical study of journal impact factors obtained using the classical two-year citation window versus a fiveyear citation window. Scientometrics [Internet]. Springer-Verlag New York, Inc.; 2011 Apr 1 [cited 2017 Jan 25];87(1):189-204. Available from: http://link.springer.com/10.1007/s11192-010-0334-1

20. Agarwal A, Durairajanayagam D, Tatagari S, Esteves SC, Harlev A, Henkel R, et al. Bibliometrics: tracking research impact by selecting the appropriate metrics. Asian J Androl. 2016;18(2):296-309. doi: 10.4103/1008-682X.171582.

21. Bergstrom C. Eigenfactor. Measuring the value and prestige. C\&RL News. 2007;68(5):314-6

22. West JD, Bergstrom TC, Bergstrom CT. The Eigenfactor ${ }^{\mathrm{TM}}$ Metrics: A network approach to assessing scholarly journals. College and Research Libraries. 2010;71(3):236-44.

23. SCImago. (2007). SJR - SCImago Journal \& Country Rank [Internet] [cited 2017 Jan 28]. Available from: http://www.scimagojr.com

24. González-Pereira B, Guerrero-Bote VP, Moya-Anegón F. The SJR indicator: A new indicator of journals' scientific prestige. Available from: https://arxiv.org/ftp/arxiv/papers/0912/0912.4141.pdf

25. Waltman L, Van Eck NJ, Van Leeuwen TN, Visser MS. Some modifications to the SNIP journal impact indicator. J Informetr. 2013;7:272-85

26. Moed HF. Measuring contextual citation impact of scientific journals. 2009;

27. Yang K, Meho LI. Citation Analysis: A Comparison of Google Scholar, Scopus, and Web of Science. 2006 . In 69th Annual Meeting of the American Society for Information Science and Technology (ASIST), Austin (US), 3-8 November 2006. Conference paper

28. Braun T, Glänzel W, Schubert A. A Hirsch-type index for journals. Scientometrics. 2006;69(1):169-73.

29. Kelly $C D$, Jennions MD. The $\mathrm{h}$ index and career assessment by numbers. Trends Ecol Evol. 2006;21(4):167-70. Epub 2006 Feb 3.

30. Hirsch JE. An index to quantify an individual's scientific research output. Proc Natl Acad Sci U S A. 2005 Nov 15;102(46):16569-72. Epub 2005 Nov 7.

31. Zhivotovsky LA, Vavilov NI, Krutovsky K V. Self-citation can inflate h-index. Scientometrics. 2008;77(2):373-5. DOI: 10.1007/s11192 006-1716-2

32. Marek Kosmulski. A new Hirsch-type index saves time and works equally well as the original h-index. Int Soc Sci Inf. 2006;

33. Egghe L. An improvement of the h-index: the g-index 1. Available from: https://doclib.uhasselt.be/dspace/bitstream/1942/983/1/an\%20impro vement.pdf 
34. Rousseau R. New developments related to the Hirsch index. Available from: http://sci2s.ugr.es/sites/default/files/files/Scientificlmpact/ Hirsch_new_developments.pdf

35. Burrell QL. On Hirsch's h, Egghe's g and Kosmulski's $h(2)$. Scientometrics. 2009;79(1):79-91. DOI: 10.1007/s11192-0090404-4

36. Sidiropoulos A, Katsaros D, Manolopoulos Y. Identification of Influential Scientists vs. Mass Producers by the Perfectionism Index. 2014 Sep 22 [cited 2017 Feb 4]; Available from: http://arxiv.org/abs/ 1409.6099

37. Scholar Mirrors: Bibliometrics, Scientometrics, Informetrics, Webometrics, and Altmetrics in Google Scholar Citations, Researcher ID, Researchgate, Mendeley, and Twitter [Internet]. [cited 2017 Jan
15]. Available from: http://www.scholar-mirrors. infoec3.es/ layout.php?id=methodology

38. San Francisco Declaration on Research Assessment. Available from: http://www.ascb.org/files/SFDeclarationFINAL.pdf

39. Hicks D, Wouters P, Waltman L, de Rijcke S, Rafols I. Bibliometrics: The Leiden Manifesto for research metrics. Nature [Internet]. $2015 \mathrm{Apr}$ 22 [cited 2017 Feb 4];520(7548):429-31. Available from: http://www.nature.com/doifinder/10.1038/520429a

40. Wilsdon J, Allen L, Belfiore E, Campbell P, Curry S, Hill S, et al. The Metric Tide Report of the Independent Review of the Role of Metrics in Research Assessment and Management. 2015 [cited 2017 Feb 4]; Available from: www.nationalarchives.gov.uk/doc/ open-governmentlicence/version/2 